RESEARCH ARTICLE

\title{
When lack of control enhances closeness to others: The case of unemployment and economic threat
}

\author{
Marcin Bukowski* (D), Soledad de Lemust (D), Rosa Rodríguez-Bailónt, Guillermo B. Willisł \& \\ Abraham Alburquerquet \\ * Jagiellonian University, Kraków, Poland \\ $†$ University of Granada, Granada, Spain
}

\author{
Correspondence \\ Marcin Bukowski, Institute of Psychology, \\ Jagiellonian University, Ul. Ingardena 6, \\ 30-060 Kraków, Poland. \\ E-mail: marcin.bukowski@uj.edu.pl \\ Received: 14 February 2018 \\ Accepted: 29 November 2018 \\ https://doi.org/10.1002/ejsp.2563 \\ Conflict of Interest Statement \\ There is no conflict of interest related to the \\ manuscript. \\ Ethical Statement \\ The authors confirm that the manuscript \\ adheres to ethical guidelines specified in the \\ APA Code of Conduct as well as authors' \\ national ethics guidelines. \\ Data Transparency Statement \\ Data from studies 1-3 is shared in a publicly \\ available repository on OSF: https://osf.io/ \\ d7xwa/?view_only=1486867e4ea84b5681 ld- \\ d5f3010789d4
}

\begin{abstract}
When personal control is threatened, people often turn to their own group and show negativity towards others. In three studies, we tested an alternative prediction that the salient lack of personal control (vs. control) experienced in the context of unemployment can lead to connectedness and more positive perception of similar others (e.g., members of groups affected by unemployment or the economic crisis). In two European countries, we found experimental (Study 1: Poland) and correlational (Study 2: Spain) evidence that a lowered sense of control of unemployed people was related to more favorable intergroup evaluations. Furthermore, when lack of control related to unemployment threat was experimentally induced, participants perceived a Greek outgroup more positively, and this effect was mediated by identification with and similarity to this group (Study 3). We discuss the role of the shared experience of collective uncontrollability in promoting positive intergroup relations.
\end{abstract}

Keywords: personal control, unemployment, group agency, intergroup perception, economic threat
Economic crises invariably leave harmful traces in the functioning of societies, groups, and individuals. They have severe social implications, such as growing rates of unemployment or social inequalities, which in turn affect the physical and mental health of individuals; this is reflected in increased levels of stress, anxiety, and a generalized sense of uncontrollability (Creed, Hood, \& Leung, 2012; Merolla, Ramos, \& Zechmeister, 2007; Riumallo-Herl, Basu, Stuckler, Courtin, \& Avendano, 2014; Warr, 1987; Wilkinson \& Pickett, 2017). Exerting personal control is a basic type of motivation and when it is threatened, people search for different forms with which to maintain or restore it (Pittman, 1998; Skinner, 1996; White, 1959). One common way of coping with uncontrollability is by self-categorizing and acting as a member of a specific social group (Bukowski, Fritsche, Guinote, \& Kofta, 2017; Fritsche et al., 2013). A self-definition in terms of "we", not only "me", can increase connectedness with other group members, helping to maintain a global sense of personal control (Stollberg, Fritsche, Barth, \& Jugert,
2017). Numerous research findings show that this group-based control restoration strategy can result in enhanced ethnocentrism, prejudice, blaming or scapegoating, and hostility towards outgroups (Becker, Wagner, \& Christ, 2011; Bukowski, de Lemus, RodriguezBailón, \& Willis, 2017; Butz \& Yogeeswaran, 2011; Fritsche et al., 2013; Greenaway, Louis, Hornsey, \& Jones, 2014; Warburton, Williams, \& Cairns, 2006). However, such defensive and palliative reactions are just one possible way of coping with social and economic threats (Fritsche, Jonas, \& Kessler, 2011; Fritsche \& Jugert, 2017). For example, the 2008 economic crisis also increased a tendency to get involved in social movements and group-based actions that are focused on solving social problems that are particularly sensitive to minority and diversity issues shared by different groups (e.g., the Indignados and anti-austerity movements in Spain; Portos, 2016). In our research we examine whether experienced lack of control can also lead to more willingness to connect with people who do not belong to the same social category. 
Considering that intergroup boundaries are malleable and context-dependent, the ingroup can also vary as a result of self-categorization level (Tajfel \& Turner, 1979; Turner, Hogg, Oakes, Reicher, \& Wetherell, 1987). For example, Giannakakis and Fritsche (2011) showed that lack of control can improve intergroup attitudes when a superordinate category that includes the in- and outgroup is made salient. In this research, existential threat (related to strong aversive feelings of lacking control; see Fritsche, Jonas, \& Fankhänel, 2008) increased positive attitudes of the British towards a French outgroup when a superordinate category of Europeans was made salient (Giannakakis \& Fritsche, 2011). Thus, there is preliminary evidence that connectedness after existential threats can take different forms, not only the one of ingroup protection. In line with these results and the group-based control restoration model (Fritsche et al., 2013), we expect that lack of control related to economic threats and unemployment can enhance connectedness with other groups. This tendency to connect with others can in turn trigger more positive intergroup evaluations and perceptions. Specifically, this should be the case when the others ("them") are viewed as similar to fellow group members ("us"), for example by being affected by the same type of socioeconomic problems.

\section{Coping With a Lack of Personal Control on a Group Level}

Experiencing a personal lack of control does not happen in a social vacuum. Groups, by providing shared goals, can enhance a sense of collective control and self-categorizing as a member of such a group can translate this collective agency to self-agency (Brewer, Hong, \& Li, 2004; Fritsche et al., 2013). Thus, the collective self (i.e., ingroup) can restore actual control over the environment, as long as the group is perceived as agentic and capable of exerting control (Stollberg, Fritsche, Barth, \& Jugert, 2017). Coping mechanisms that rely either on protecting the ingroup or acting on its behalf are useful only if the ingroup provides resources that restore the personal sense of control (Stollberg, Fritsche, \& Bäcker, 2015). For example, when personal control is threatened and the group's collective agency is lowered, people might still get involved in group-based actions (Fritsche et al., $2013,2017)$. However, research showed that individuals look for ingroup support only when the difficulty of the required actions that needed to be taken was moderate; that is, the goal was perceived as achievable at the group level (Fritsche et al., 2013). This type of ingroup support would probably be weakened or disappear when personal control restoration by involvement in actions on behalf of the ingroup is perceived as highly difficult or pointless. Thus, enhancing bonds within one's own group might not be an effective coping strategy when control cannot be easily restored on an ingroup level. Instead, searching for closeness and similarity with other people, despite their different category membership, might appear as an adaptive strategy to cope with uncontrollability.

A tendency to connect with others, including potential outgroup members, should be especially appealing when belonging to a certain social category is burdened with stigmatization, as it is for example in the case of people who are unemployed (Goffman, 1963). Previous research on stigma-based solidarity has shown a tendency to form coalitions among members of different stigmatized or disadvantaged groups (Craig \& Richeson, 2012, 2016). A salient disadvantaged position could trigger a common social group category with members of other social categories who are in a similar socioeconomic situation and who share a common fate or goal (Campbell, 1958; Gaertner \& Dovidio, 2000). We argue that in the case of unemployment and economic threats, low personal control and collective uncontrollability could promote identification with other groups that face similar social and economic problems. This issue remains fairly underexplored in the literature and seems to be highly relevant, especially in the aftermath of the global economic crisis and its sociopsychological effects.

\section{Unemployment, Uncontrollability, and Intergroup Perception}

People who are unemployed or those who experience a realistic threat of being unemployed (e.g., graduating students in times of economic crisis) show enhanced levels of psychological distress and a chronic sense of low personal control (Hannan, O'Riain, \& Whelan, 1997; Murphy \& Athanasou, 1999; Price, Choi, \& Vinokur, 2002). They face difficulties in changing their situation on the personal level and suffer from a negative social stereotype that gives rise to a negative selfcategorization and group identity (Cassidy, 2001). Because a negative group identity of people who are unemployed is mainly rooted in their low group agency, the reliance of group-based coping strategies, including acting on behalf of the ingroup and expressing ingroup bias and negativity towards outgroups, can be reduced (Creed \& Bartrum, 2008). We propose that because people who are unemployed (or threatened by stable unemployment in the context of an economic crisis) face a social constraint in the form of a reduced ability to restore personal control within their own social group, they are prone to identify with groups affected by the global economic crisis and probably also use a different, broader social categorization of people who experience similar socioeconomic conditions. This change in the self-categorization, which paves the way to perceptions of intergroup similarities and a sense of closeness with members of other social categories who share a common fate, might appear as a valid means to restore a personal sense of control. In sum, we predict that lacking personal control can lead to a specific form of connectedness with similar others, 
which might result in more closeness and less prejudice towards members of those groups.

Could this state of collective uncontrollability of people who are unemployed change the social perception of some specific types of groups? Based on previous literature, it can be determined that important boundary conditions for inclusive categorization and proximity towards outgroups need to occur. One is the initially perceived similarity with the outgroup; highly dissimilar ones are more prone to be devaluated (Cikara, Bruneau, \& Saxe, 2011). Furthermore, highly threatening groups enhance prejudice, especially in times of economic strain (Butz \& Yogeeswaran, 2011). In sum, we expect more inclusive and positive reactions to social groups that face similar conditions of economic disadvantage and that are not directly threatening resources of the ingroup.

\section{Overview of the Studies}

We performed three studies to test whether unemployed people who perceive personal uncontrollability (vs. personal controllability) show more positive intergroup perceptions and evaluations. In the first study, by using an experimental design, we reminded Polish unemployed people of instances in their life related to having or not having control and assessed the evaluations of an immigrant group. In the second correlational study, we assessed sense of control, intergroup evaluations and outgroup blaming in a Spanish unemployed sample during a period of economic crisis (i.e., of high unemployment rates). In the third study, we experimentally manipulated personal control among last-year students via a fictitious newspaper article that primed a perception of negative consequences of the economic crisis in Spain regarding the possibility of being employed after graduation. We measured participants' social perception of an outgroup also affected by the economic crisis (i.e., Greeks) and assessed identification, similarity perceptions, and solidarity with the outgroup.

\section{Study 1}

In this study we examined how experiences of having or lacking control shape intergroup attitudes among unemployed people towards a recognizable immigrant group in Poland (i.e., immigrants from former Soviet republics) using a mindset-priming manipulation. Previous literature showed increased prejudice after control threats evoked by an economic crisis (Becker et al., 2011; Butz \& Yogeeswaran, 2011; Greenaway et al., 2014), which is why in this study we focused mainly on prejudice measures. We used a direct and an indirect operationalization of prejudice (outgroup evaluations and the Symbolic Racism Scale [SRS] vs. pen and pencil Implicit Association Test [IAT]) because we assumed that the effects of control threat on intergroup relations are sometimes subtle and could be subject to desirability concerns in responses. We expected to find relatively lower levels of prejudice among those participants who recalled instances of lacking control in their life compared to those who recalled situations in which they had control. Specifically, we expected to observe less explicit prejudice (Symbolic Racism Scale [SRS]), and more positivity towards the immigrant group on evaluative components of intergroup perceptions, and on an implicit evaluative measure (paperpencil IAT) after exposure to uncontrollability.

\section{Method}

Participants. Sixty-seven unemployed adults registered in the regional labor office in the Kraków, Małopolska region of Poland and participated in the study in June 2011. Data exclusion criteria referred to the understanding of the instructions of the manipulation and ability to generate a memory consistent with the instruction (i.e., low control vs. high control). People who provided the opposite type of description and marked the highest, opposite score on the sense of control scale were excluded from further analyses. Overall, four participants in the lack of control condition reported feeling full control (highest score on the manipulation check scale) after recalling an uncontrollable event and therefore were not included in further analyses. The exclusions did not change the pattern of obtained results. The final sample comprised 63 participants (40 women and 22 men, one unreported), with a mean age of 38.54 years $(S D=11.36$; age range: 20 $59)$, and a mean unemployment length of 27.48 months $(S D=37.29)$. A total of $73 \%$ indicated that they did not receive any governmental financial support, and $27 \%$ noted that they received help. The nationality of all participants was Polish. Upon completing the study, participants were thanked, debriefed, and received a compensation of 10 PLN (approximately $\$ 2.5)$. We conducted a sensitivity analysis using G*power (Faul, Erdfelder, Lang, \& Buchner, 2007). Results showed that with this sample size $(N=63)$, the minimum effect size that we can detect for $\alpha=.5$ and $1-\beta=.80$ is $f=.36$ (minimum detectable effect). ${ }^{1}$

Procedure. Participants who arrived at the regional labor office to take part in an informational program about searching for possible employment offers were asked to participate in a study on the psychological

\footnotetext{
${ }^{1}$ Data for Studies 1 and 2 was collected in 2011. At that time, the research practice of estimating sample sizes based on power calculations was not so widespread, and unfortunately, we did not perform a priori power analyses. For Study 1 we used as a rule of thumb " $n=30$ per condition", which was a common practice at that time for ANOVA designs (e.g., Wilson VanVoorhis \& Morgan, 2007). Also, we were constrained by the availability of unemployed people to participate in our studies (the data collection process was controlled by the unemployment offices) and it was very difficult to complete the samples in the first two studies. We performed sensitivity analyses to check for the minimum detectable effects for $\alpha=.5$, and $1-\beta=.80$. We did not apply a post-hoc power analysis since it is generally not recommended (Hoenig \& Heisey, 2001; Zumbo \& Hubley, 1998).
} 
consequences of being unemployed. The first part of the survey included questions regarding demographics and issues related to the state of unemployment (length, financial help from the government, participation in courses for unemployed people, etc.). Following this, participants were asked to fill out two questionnaires measuring individual differences in control and epistemic motivation. ${ }^{2}$ They then followed a control manipulation procedure, which was introduced to the participants as a memory measure regarding experienced past events.

Control manipulation. We administered a mindsetpriming manipulation of personal control that was based on previous research (Whitson \& Galinsky, 2008) to temporarily reduce or to enhance participants' sense of control. In the low control priming condition, participants read, "Please recall a situation from your life in which you had no control or influence on what was happening. Describe the situation below as accurately as possible. What exactly happened, what did you feel, etc.?" In the high control priming condition, the instructional wording was identical, but participants were asked to recall a situation in which they had control. Three items serving as manipulation checks followed the control mindset-priming procedure ("To what extent was the situation described above related to a sense of control/lack of control?", "To what extent did the situation described above evoke a sense of control/lack of control?", and "Did you experience difficulty in recalling the situation described above?"). Answers to all of these items were marked on a 5-point scale, ranging from 1 (not at all) to 5 (very much).

In the next part of the study, we asked the participants to answer a set of questions that addressed the issue of how immigrants from former Soviet republics are currently perceived in Poland. The category Immigrants from former Soviet republics includes mainly people from such countries as Ukraine and Belarus, but also includes a smaller number of immigrants from Georgia and Armenia. Ukrainians have formed the largest immigrant group in Poland since 2011 (https://ud sc.gov.pl/). Importantly, cultural and historical commonalities could be perceived with people immigrating from Ukraine or Belarus.

Implicit Association Test. To measure implicit prejudice in a context that does not allow the use of a computerized version of the IAT test, we administered a paper-pencil version of the IAT (Lemm, Lane, Sattler, Khan, \& Nosek, 2008). The stimuli were adapted to the Polish ingroup (typical Polish names as categories) and the outgroup of immigrants from Soviet republics (Poles and Russians were categorical labels for in- and outgroups, and typical names for both categories served as specific examples). The test consisted of a

\footnotetext{
${ }^{2}$ Desirability of Control (Burger \& Cooper, 1979) and Need for Cognitive Closure (Kossowska, Hanusz, \& Trejtowicz, 2012) scales were administered. No moderation effects were observed.
}

prejudice-neutral phase and two phases of consistent and inconsistent pairings between Polish versus Russian and positive versus negative adjectives. Each test phase involved 40 test trials and was administered on a separate page. Participants were given 20 seconds for each phase to mark one of two possible category pairings. The difference in the number of correctly marked answers in the inconsistent and consistent parings indicated the implicit association bias.

Intergroup attitudes. We applied the open-ended attitude measure to assess evaluations of immigrants from former Soviet republics (Esses \& Zanna, 1995). Participants were asked to generate a maximum of 10 typical characteristics of immigrants from former Soviet republics. Upon completing this task, they were asked to read again each characteristic and rate it on a 7 -point scale, ranging from -3 (very negative valence) to +3 (very positive valence).

Social threats. Threats imposed by immigrants from former Soviet republics were measured using four items. Threats related to the security of Polish citizens, the Polish labor market, the values of Polish society, and Polish culture and traditions were assessed $(\alpha=.85)$. Items were rated on 7 -point scale $(1=$ not at all; $7=$ very much).

Prejudice. As a prejudice measure, we applied a 15item version of the SRS $(\alpha=.73)$. Items in both scales were rated on 5 -point Likert scale ( $1=$ strongly disagree; 5 = strongly agree; Sears, 1988).

Causes of the economic crisis. At the end, participants were given a list of six causes of the economic crisis and were asked to assess its importance. The causes considered were governmental politics, economic cycles, the global economic system, powerful groups and institutions, the lifestyles and work habits of the citizens, and immigrants. Items were rated on 7 point scale $(1=$ not at all; $7=$ very $m u c h)$.

\section{Results}

We performed univariate ANOVAs to test for the main effects of control manipulation on each dependent variable.

Manipulation check. Participants in the low control condition scored significantly lower on items assessing to what extent the described situation induced control, low control: $M=2.71, S D=1.56$; high control: $M=4.39, S D=0.90 ; F(1,59)=27.53$, $p<.001, \eta^{2}=.32$, and whether they experienced control upon remembering this situation, low control: $M=2.38, \quad S D=1.18 ; \quad$ high control: $\quad M=4.30$, $S D=0.92 ; F(1,60)=52.09, p<.001, \eta^{2}=.46$. There was no difference in the assessed difficulty of recalling instances of both situations, $F(1,59)=1.39, p=.24$, $\eta^{2}=.02$. 
Implicit prejudice. There were no differences in the IAT score between experimental conditions, low control: $M=2.51, S D=4.60$; high control: $M=2.30$, $S D=4.23 ; F(1,60)=0.03, p=.849, \eta^{2}=.001$. This lack of differences between conditions should be, interpreted with caution, however, as we observed large differences between individuals' ability to follow the instructions for performing this task (the standard deviations for this measure were very high, which could be an indicator that it did not work properly).

Open-ended attitude measure. We found significant differences between experimental conditions, showing more positive attitudes among participants primed with a lack of control than those primed with control, low control: $M=0.85, S D=1.8$; high control: $\quad M=-1.40, \quad S D=1.73 ; \quad F(1,58)=4.62$, $p=.036, \eta^{2}=.07$.

Social threats. We did not observe significant differences between experimental conditions, low control: $M=2.41, S D=1.33$; high control: $M=2.82$, $S D=1.49 ; F(1,60)=1.28, p=.263, \eta^{2}=.02$.

Explicit prejudice. Similar to the attitudes measure, we observed lower prejudice scores for the low control condition than for the high control condition, low control: $M=2.53, S D=0.57$; high control: $M=$ 2.86, $S D=0.51 ; F(1,60)=5.44, p=.023, \eta^{2}=.08$.

Causes of the economic crisis. We performed a multivariate ANOVA to check whether the control manipulation influenced the causes (attributions of blame) of the economic crisis; no differences between groups were observed for the overall interaction, $F(6$, $44)=1.39, p=.241, \eta^{2}=.16$, or for any specific cause (all Fs $<1$ ).

\section{Discussion}

This study showed that unemployed people who were reminded of a situation in which they did not have control expressed more positive attitudes and less explicit prejudice towards a salient immigrant group than those who recalled a situation in which they were in control. We did not find any differences in implicit prejudice, which was most probably due to methodological issues related to a largely varied sample in terms of age and the low familiarity of our participants with such measures. Despite this, in line with our main prediction, when low (vs. high) personal control was made salient, people who were unemployed revealed less prejudice and more positive attitudes. Presumably expressing prejudice towards a minority group did not serve as an opportunity to restore a personal sense of control for those who were unemployed. A coping strategy that is based on outgroup derogation could be observed in standard populations when threats to personal control were activated (Greenaway et al., 2014). However, people who experience a personal lack of control and have a low ability to restore their control on a group level (due to a salient self-categorization of being unemployed) might not use this coping strategy. On the contrary, reminders of uncontrollability could direct unemployed people to connect with others (also other social category members) as a potential means by which to restore personal control. However, our sample size was too small to ensure confidence about the reliability of these results. Therefore, it is important to consider additional converging evidence from other samples. In Study 2, we focus on this phenomenon using a sample of unemployed people from a different country (Spain).

\section{Study 2}

In this study, we used a correlational design to examine how a sense of personal uncontrollability experienced by unemployed people in Spain is related to their perceptions and evaluations of immigrant groups. The economic crisis that heavily affected Spanish society during 2008 threatened people's basic psychological needs for control and predictability (Bukowski, de Lemus, et al., 2017). We recruited a sample of unemployed people who directly faced the negative effects of the crisis in their lives and assessed how their feelings of control are related to social perception and prejudice towards immigrant outgroups. In this study we focused on direct, evaluative measures of prejudice but also explored other components of social perception related to the BIAS map model (Cuddy, Fiske, \& Glick, 2007), that is, warmth and competence, intergroup emotions and behavioral tendencies. We expected that people who perceive their situation to be more uncontrollable will show less prejudiced and more positive perceptions of immigrants than those who maintain a sense of controllability, despite being unemployed. Additionally, we focused on factors that can be related to lower levels of prejudice among the unemployed who experience lack of control, such as specific attributions of causes of the economic crisis and perceptions of similarity to immigrant groups. We predicted that unemployed people who have a low personal sense of control experience similarity with them, as they share a sense of common fate. Thus, we explored whether uncontrollability is positively related to perceived similarity with the outgroup and attributions of causes of the economic crisis (to immigrants vs. powerful groups). We also explored the effects of uncontrollability on social perception (competence, warmth, emotions, and behavioral tendencies) of those groups.

Still, not all types of outgroups might be perceived and evaluated equally as a function of personal control. We included two outgroups that differed in the levels of perceived realistic threat (i.e., immigrants from Morocco and Eastern Europe) to check whether 
the expected effects would depend on the outgroup. A previous study performed on a Spanish student population (Bukowski, de Lemus, et al., 2017; Study 1) ${ }^{3}$ indicated that East European immigrants are perceived to impose a stronger realistic threat than Moroccans. Furthermore, previous research has shown that perceived similarity and ingroup bias were negatively related for non-threatening outgroups (HendersonKing, Henderson-King, Zhermer, Posokhova, \& Chiker, 1997). We planned to perform exploratory analyses to determine whether higher similarity and lower prejudice ratings would only be observed for the lessthreatening Moroccan outgroup.

\section{Method}

Participants. Seventy-one people who were unemployed (42 women and 29 men) registered at the employment office in Albolote in the Andalucía region of Spain to participate in the study in 2011. Their age ranged from 17 to 64 years, with a mean age of $34.51(S D=9.42)$. The mean length of unemployment period was 21.10 months $(S D=17.39)$, and $28.6 \%$ received governmental aid. The nationality of participants was Spanish. Sensitivity analyses showed that with the total sample $(N=71)$, the minimum detectable effect for $\alpha=.5$ and $1-\beta=.80$ is $\rho=.32$, whereas for the split analyses $(n=36 ; n=35)$, the minimum detectable effect is $\rho=.41$.

Measures. Participants were asked to fill out a questionnaire about the psychological effects of the economic crisis on their lives. Firstly, three individual difference measures were administered. ${ }^{4}$ Then the following measures were completed. All items were rated on 7 -point scale $(1=$ not at all; $7=$ very much $)$, unless indicated otherwise.

Personal control related to the economic crisis. As in previous studies (Bukowski, de Lemus, et al., 2017), we measured two aspects of perceived control. The first aspect measured was the impact of the crisis on feelings of low control (e.g., "To what extent does the crisis make you feel that you have no control over the things that happen to you?"; two items' $\alpha=.64)$. The second aspect assessed personal control over the effects and development of the crisis ("To what extent can you do something to change the effects of the

\footnotetext{
${ }^{3}$ This previous study has been published elsewhere (Bukowski, de Lemus, et al., 2017). A $t$-test comparison revealed a significant difference between the amount of threat attributed to Moroccans versus East Europeans, $M_{\mathrm{M}}=2.68 ; M_{\mathrm{EE}}=3.39 ; t(108)=-3.06, p=.003, \mathrm{CI}$ $(-1.17,-0.25)$.

${ }^{4}$ Desirability of Control (Burger \& Cooper, 1979), Need for Cognitive Closure (Kossowska et al., 2012) and Social Dominance Orientation (Pratto, Sidanius, Stallworth, \& Malle, 1994) were also measured. Since those constructs were part of a larger dataset and were not directly related to the purpose of this research they are not described in detail here. The data is available on the OSF platform.
}

economic crisis on your life?"; three items' $\alpha=.77$ ). Two items were excluded, as they reduced the reliability of the scales.

Causes of the economic crisis. Participants were given a list of six causes of the crisis and were asked to respond to what extent they considered each item to be a cause of the economic crisis: governmental politics, immigrants, the global economic system, influential groups and institutions (bankers, multinational corporations), the lifestyles and work habits of the citizens, and typical fluctuations in the global economy.

In the next part of the survey, participants were informed that a set of questions regarding the perception of immigrant groups in Spain would follow. Participants were randomly assigned to one of two conditions (types of survey), one asking them to evaluate Moroccan immigrants and the asking them to evaluate other East European immigrants on the following measures.

Social threats. Threats related to immigrants were measured using three items assessing the threat that Moroccan/East European immigrants pose to the security of Spanish citizens, the labor market, and to the values of Spanish society $(\alpha=.84)$.

Social perception. Four items measured perceived stereotype contents (Fiske, Cuddy, Glick, \& Xu, 2002): Two were related to the dimension of competence ("competent", "capable"; $r=.57$ for Moroccans, and $r=.84$ for East Europeans), and two were related to warmth ("cordial", "kind"; $r=.74$ for Moroccans, and $r=.91$ for East Europeans). We included single-item measures of specific emotions evoked by the two immigrant outgroups: admiration, contempt, pity, envy, fear and anger, and four items measuring behavioral tendencies towards the outgroup: to help, attack, cooperate, and exclude (Cuddy et al., 2007).

Modern Racism Scale. Ten items measured the level of prejudice towards immigrants in Spain $(\alpha=.78$ for the Moroccan subscale, removing one item, and $\alpha=.79$ for the East European subscale; McConahay, Hardee, \& Batts, 1981; Spanish adaptation by Navas, 1998).

Symbolic Racism Scale. A 15 items version of the scale was used $(\alpha=.73$ for Moroccans, and $\alpha=.81$ for East Europeans). Items in both scales were rated on 5point Likert scale ( 1 = strongly disagree; $5=$ strongly agree; Sears, 1988; Spanish version by Martínez $\delta$ Vera, 1994).

Similarity perception. General similarity of the Spaniards with the outgroup (East Europeans or Moroccans) was measured using one item ("How different or similar are the East Europeans/Moroccans from the 
Spaniards in general?"). Participants were asked to mark their answer on a 7-point Likert-type scale, ranging from 1 (totally different) to 7 (the same). Following this item measuring general difference versus similarity, participants were asked to assess similarity related to specific domains of life. Eight items, also measured on a 7-point scale, concerned the following aspects: values, religious beliefs and practices, style of living, work habits, types of jobs performed, job expectancies (salary, type of employment, etc.), beliefs about gender relations, and hygienic habits. An average score was computed for the scale (overall $\alpha=.90 ; \alpha=.89$ for Moroccans, and $\alpha=.91$ for East Europeans).

At the end of the survey, specific items related to participants' current emotional state and identification were administered.

\section{Results}

We first report results considering the two outgroups (Moroccans, and East Europeans) together and then the analyses separating both groups.

Overall analyses. Firstly, we focused on the two components of perceived control measured (i.e., the impact of the crisis on feelings of control; $M=5.54$, $S D=1.39$, and personal control over the development of the crisis; $M=3.93, S D=1.53$ ) and checked how they were related to the measures of prejudice, threat, or social perception for the two outgroups (Moroccans and East Europeans). There were no significant correlations between the impact of the crisis on the feelings of control, prejudice, or social perception measures (all $p s>.25)$. Perceived lower personal control over the effects and development of the crisis was related to lower scores on both prejudice measures; that is, the MRS $(r=.30,95 \%$ CI $[0.14 ; 0.56], p=.002)$ and the SRS towards immigrants $(r=.29,95 \%$ CI [0.06; 0.49], $p=.016)$, supporting our prediction.

Split analyses by outgroup. Secondly, we examined the correlations separately for both outgroups (Moroccans: $n=35$; Eastern Europeans: $n=36$ ), considering previous evidence indicating that East Europeans were perceived to be more threatening than Moroccans in Spain when the survey was conducted (Bukowski, de Lemus, et al., 2017). Furthermore, also in the current study the two outgroups tended to differ in the realistic threat they imposed to security, the Moroccans being the outgroup that activated less threat, for Moroccans $M=3.91, S D=1.70$, and for East Europeans $M=4.75, S D=1.98 ; t(69)=-1.91$, $p=.061, d=-0.45$. Thus, we examined whether the relationship between low personal control and less prejudice mainly held for the less-threatening outgroup (i.e., Moroccans).

Control and prejudice. There was no relationship between the impact of the crisis on feelings of control and prejudice towards Moroccan or East European immigrants (see Table 1 for correlations). However, low personal control over the effects and development of the crisis correlated positively with less prejudice towards Moroccan immigrants (MRS: $r=.53,95 \% \mathrm{CI}$ [0.23; 0.73], $p=.001$; SRS: $r=.32,95 \%$ CI [-0.2; 0.59 ], $p=.065$ ) and positively but non-significantly with less prejudice towards East European immigrants (MRS: $r=.21,95 \%$ CI $[-0.10 ; 0.53], p=.24$; SRS: $r=.28,95 \%$ CI $[-0.24 ; 0.43], p=.11)$.

Social perception. Regarding the social perception measures, we ran some exploratory analyses and found no relationships between control and stereotype content (competence and warmth). Lower personal control over the effects and development of the crisis was related to lower perceived envy towards East European immigrants $(r=.39,95 \%$ CI [0.06; 0.64], $p=.024)$. Interestingly, higher assessed negative impact of the crisis on feelings of control was related to higher perceived social exclusion of Moroccan immigrants in Spain $(r=.38,95 \%$ CI [0.5; 0.63], $p=.027)$. No other correlations between control and social perception, emotions, or behavioral tendencies were significant (see Table S1 in Supporting Information). Because people who are unemployed make up a social group that is also likely to be socially excluded within its own society, it seems important to relate this finding with similarity perceptions between people who are unemployed and Moroccan immigrants. In fact, a positive correlation between the perceived social exclusion of Moroccans and a sense of similarity with their group could be observed $(r=.42,95 \%$ CI $[0.09 ; 0.66], p=.015)$.

Perceived similarity. We also ran exploratory analyses to check the relationship between sense of control and perceived similarity of the two outgroups. We found some non-significant trends, suggesting a relationship between the perceived impact of the crisis on feelings of control and the similarity assessment between the Spanish ingroup and Moroccans. Participants who reported feelings of low control caused by the crisis tended to perceive Moroccans - the less threatening outgroup - as more similar to them in general $(r=.29,95 \%$ CI $[-0.05 ; 0.57], p=.09)$ and in terms of specific aspects of values, beliefs, norms, and habits $(r=.33,95 \%$ CI $[-0.01 ; 0.59], p=.06)$. This positive correlation was completely absent and non-significant for the East European immigrant outgroup $(r=.03, p=.86)$.

Blaming. In the next step, we checked whether specific attributions (causes) of the crisis are related to participants' sense of control and whether they account for differences in expressed prejudice towards the outgroup or perceived similarity with the outgroup. Overall analyses revealed that a sense of low control caused by the crisis was positively correlated with blaming the government $(r=.37,95 \%$ CI $[0.15$; 0.56], $p=.001$; split analyses: for Moroccans, $r=.40$, 
Table 1. Partial correlations between perceived control, causes of the economic crisis, and prejudice towards Moroccan immigrants (top part) and East European immigrants (bottom part of the table) in Study 2

\begin{tabular}{|c|c|c|c|c|c|c|c|c|c|c|c|c|c|c|}
\hline & $\begin{array}{c}\text { Mean }_{\text {Mor }} \\
(S D)\end{array}$ & $\begin{array}{c}\text { Mean }_{\text {Eur }} \\
(S D)\end{array}$ & 1 & 2 & 3 & 4 & 5 & 6 & 7 & 8 & 9 & 10 & 11 & 12 \\
\hline $\begin{array}{l}1 \text { Impact } \\
\text { of crisis } \\
\text { on control }\end{array}$ & $5.37(1.53)$ & $5.60(1.37)$ & & .03 & $.40^{*}$ & .33 & .36 & .11 & .17 & .16 & .31 & -.12 & .13 & .29 \\
\hline $\begin{array}{l}2 \text { Control } \\
\text { over crisis }\end{array}$ & $4.17(1.56)$ & $3.67(1.45)$ & .08 & & .04 & .20 & .33 & -.01 & -.03 & .27 & .12 & $.53^{* *}$ & .32 & .10 \\
\hline $\begin{array}{l}3 \text { Cause: } \\
\text { government }\end{array}$ & $4.83(2.24)$ & $5.53(1.84)$ & .32 & .05 & & $.57^{*}$ & .31 & .33 & .30 & .14 & .14 & -.15 & -.04 & $.39 *$ \\
\hline $\begin{array}{l}4 \text { Cause: } \\
\text { economic } \\
\text { system }\end{array}$ & $4.86(1.85)$ & $6.14(1.29)$ & -.17 & -.09 & .04 & & $.68^{* *}$ & .06 & .25 & .28 & -.06 & .12 & -.11 & $.37 *$ \\
\hline $\begin{array}{l}5 \text { Cause: } \\
\text { powerful } \\
\text { groups }\end{array}$ & $5.49(1.67)$ & $6.21(1.17)$ & -.06 & .02 & .03 & .31 & & .20 & .12 & $.38^{*}$ & -.13 & .11 & -.10 & .14 \\
\hline $\begin{array}{l}6 \text { Cause: } \\
\text { immigration }\end{array}$ & $4.09(1.88)$ & $3.91(2.15)$ & .12 & .18 & $.36^{*}$ & .02 & -.01 & & .31 & .32 & $.42^{*}$ & .09 & -.11 & .17 \\
\hline $\begin{array}{l}7 \text { Cause: } \\
\text { lifestyle }\end{array}$ & $4.21(1.74)$ & $4.94(1.82)$ & -.04 & .32 & .18 & -.03 & -.15 & .29 & & $.57 * *$ & .19 & -.05 & -.04 & .28 \\
\hline $\begin{array}{l}8 \text { Cause: } \\
\text { economic } \\
\text { cycles }\end{array}$ & $4.54(1.80)$ & $5.08(1.73)$ & -.22 & .02 & -.07 & $.36^{*}$ & .19 & .26 & .09 & & .25 & .12 & -.13 & .07 \\
\hline 9 Social threats & $4.25(1.36)$ & $4.56(1.80)$ & .17 & .24 & .14 & -.20 & -.07 & $.67 * *$ & .14 & .07 & & .10 & $.39 *$ & .29 \\
\hline $\begin{array}{l}10 \text { Modern } \\
\text { Racism Scale }\end{array}$ & $3.26(.81)$ & $3.22(.81)$ & .13 & .21 & .10 & -.22 & .11 & $.58 * *$ & .15 & .15 & $.79 * *$ & & $.40^{*}$ & .08 \\
\hline $\begin{array}{l}11 \text { Symbolic } \\
\text { Racism Scale }\end{array}$ & $2.98(.53)$ & $2.95(.75)$ & .16 & .28 & .06 & -.09 & .23 & $.49 * *$ & -.04 & -.04 & $.60 * *$ & $.60 * *$ & & .00 \\
\hline 12 Similarity & $4.23(1.49)$ & $4.10(1.48)$ & .03 & .08 & -.15 & -.18 & -.33 & .12 & .19 & .19 & .04 & .03 & -.29 & \\
\hline
\end{tabular}

Note: Significant correlations are marked as: $* * p<.01, * p<.05$. Sample sizes for the Moroccan outgroup vary between $N=33$ and $N=35$, for the East European outgroup between $N=34$ and $N=36$ as a function of missing data. Means and standard deviations are depicted separately for both groups.

$95 \%$ CI $[0.08 ; 0.64], p=.017$; for East Europeans, $r=.32,95 \%$ CI $[-0.01 ; 0.58], p=.054)$. Interestingly, neither a lack of control caused by the crisis nor a sense of control over the effects of the crisis was related to blaming immigrants as a cause that contributed to the development of the crisis.

\section{Discussion}

In this study, we found that a decreased sense of control in the context of unemployment and the economic crisis was positively related to lowered levels of prejudice against immigrants. This result partially replicates the one from Study 1, which also revealed relatively weaker prejudice after priming uncontrollability relatively to control. Importantly, in this study, we moved to a socially different context, Spain, a country that, at the time of data collection, was affected by a strong wave of the global economic crisis that enhanced the perceptions of collective uncontrollability (Fritsche et al., 2017). This means that, compared to the study performed in Poland, in this study unemployed participants were not only in an uncontrollable situation due to their employment status, but that the economic situation of the country they lived in largely decreased the chances of finding employment. This difficult socioeconomic situation probably reduced the tendency to apply strategies to restoring control related to enhanced ingroup bias or expression of prejudice towards outgroups. Instead, a personal lack of control accompanied by collective uncontrollability related to the economic crisis boosted similarity perceptions with the Moroccan outgroup. This result provides initial evidence for our assumption that more positive intergroup relations among people who experience uncontrollability are related to a perception of similarity and closeness towards others.

Interestingly, this study revealed that people who reported that their sense of control was negatively affected by the crisis were also more prone to blame the government and powerful outgroups for their misfortune, but not immigrants. When faced with a lack of control that is difficult to change by referring to a powerful ingroup, quick fixes, such as blaming immigrants, do not solve the problem in the long term. Instead, a more inclusive perception of other groups that face similar social problems seems to be a more rational strategy to deal with uncontrollability. This interpretation is in line with some previous findings, showing that existential threat does not necessarily lead to ingroup bias when one's group is recategorized on a different level (e.g., students and not English vs. Scottish people; see Giannakakis $\delta$ Fritsche, 2011). In our research, unemployed Spanish 
people might perceive immigrants as being similar to them because they are also affected by low employability. However, the remaining question is whether such similarity could enhance more positive intergroup perceptions. If this is the case, could it be due to higher perceived identification and similarity with others?

\section{Study 3}

In this study, we examined whether personal lack of control can lead to more positive perceptions and evaluations of a distinct group that could be categorized as being in a similar socioeconomic context due to the economic crisis (e.g., Greeks). The common group categorization that would apply in this context could include countries that are heavily affected by the economic crisis in Europe (in this case, Greece and Spain). This common context and having finances being monitored by external institutions, such as the Central Bank, could activate a common category, increasing identification with the outgroup and a perception of similarity between Spanish and Greeks. In fact, previous research showed that perceived common fate, such as in the face of a natural disaster, created a shared identity with outgroup members (Drury, Brown, González, \& Miranda, 2016). An outgroup that is perceived to share a common fate with the ingroup is not threatening; hence, it would not trigger ethnocentric responses, but could rather aid in restoring control. According to the self-categorization theory (Turner et al., 1987) and the dual-identity model (Dovidio, Gaertner, \& Validzic, 1998; González \& Brown, 2003), people are perceived as being more similar if they share some common identity, which has a positive impact on intergroup relations (e.g., social support or solidarity). Wirtz and Doosje (2013) found that the perceived similarity of minority group members mediated the effect of identity on the evaluations of the outgroup. Hence, we predicted that personal lack of control accompanied by realistic unemployment threat will increase identification with the Greeks, which in turn will lead to higher perceived similarity, resulting in more positive outgroup perceptions (Brown, 1984). Finally, we also expected that low control experienced by young Spaniards in the context of the economic crisis will lead to more solidarity with Greeks due to increased perceptions of shared identity and similarity.

We evoked control or lack of control perceptions by manipulating the perspective of stable negative versus improving trends of unemployment in Spain and measured social perception of Greeks, as well as identification with, similarity to, and solidarity with the Greek outgroup. In this case, we did not focus on explicit measures of prejudice. Considering the cultural similarities between Greece and Spain, we assumed low levels of explicit prejudice towards Greeks. In France and Germany, Greeks are perceived as the least trustworthy people in Europe; however, this is not the case for Spain (Pew Research Center, 2013). For this reason, we decided to focus on social perception (Fiske et al., 2002) instead, to examine whether shifts in perception of competence and warmth take place after control threats.

\section{Method}

Participants. One hundred and six participantsstudents from different Spanish universities located in the southern part of the country-took part in an online study. The data exclusion criteria were the same as in Study 1, that is, people who provided the opposite type of description and marked the highest, opposite score on the sense of control scale were excluded from further analyses. Two participants from the controllability condition were excluded because they explicitly disagreed with the credibility of the article presented as control manipulation and declared lowest level of control (i.e., lowest score on the personal control manipulation check); one participant was also excluded from the uncontrollability condition who reported having a secure job and marked the highest score on the personal control scale. The exclusions did not change the pattern of obtained results. The final sample comprised 103 participants (68 women and 35 men). Age data were not collected. All the participants were third- and fourth-year graduate students from the social and medical sciences. This sample choice was justified by the fact that in the last two years before graduation the concern about unemployment is much higher than for younger students. The nationality of all participants was Spanish. The study took place in May 2015. Sensitivity analyses showed that with this sample size $(N=106)$, the minimum detectable effect for $\alpha=0.5$ and $1-\beta=.80$ is $f=.28$.

Procedure. The students were asked to voluntarily take part in a study that concerned employment issues in Spain and the perception of social groups. The study was designed using Qualtrics software (https://www. qualtrics.com/) and was accessible online. After being informed that the study was fully anonymous and that they could resign from participation at any moment, participants were asked to read an article placed in an online newspaper.

Uncontrollability manipulation. A fictitious article in an online version of the newspaper Expansión was presented to the participants. The article was about the situation in the current labor market in Spain, specifically the employability perspectives for young people. It is important to emphasize that the unemployment issue was very salient at the time of data collection; the unemployment rate in Andalucía, Spain, for young adults (under 25 ) was $57.61 \%$ (INE, 2015). To make salient a sense of lack of control 
versus control related to the stability of the economic crisis and the chances to be employed in the near future, two versions of the newspaper article were prepared and randomly distributed across participants. In the lack of control condition, participants read that the situation in the labor market in Spain maintained the same and that it had even worsened lately, decreasing the chances for employment. In the controllable condition, the article stated that the situation was slowly getting better and that the predictions for the near future were positive. Upon reading the article, participants were asked to think about the news for a while and to answer a few questions in writing related to the article. The questions follow: (i) How does this situation described above affect your future aspirations? Please give an example how it can influence your personal life. (ii) Do you feel that you have control to decide what you want to do in your life? Please justify your response. The questions were identical in both experimental conditions.

Manipulation check. Three items measuring perceived control followed the manipulation: (i) To what extent do you feel in this moment that you have control over your life? (ii) To what extent do you feel that the crisis makes you feel lack of control over the things that happen in your life? (iii) To what extent do you feel that you have control over the development of the crisis? The second and third items were also applied in Study 2; they were adapted from a scale used in our previous research (Bukowski, de Lemus, et al., 2017). An average score was not calculated, as each item concerned different aspects of personal control. Items were rated on 5-point scale $(1=$ not at all; $5=$ very $m u c h)^{5}$

Social perception. Next, we measured the perceived stereotype content (competence and warmth) of the Greeks using four items: Two related to the dimension of competence ("competent", "capable"; $r=.86$, $p<.001$ ) and warmth ("cordial", "kind"; $r=.90$, $p<.001)$. All items were rated on a 7 -point scale $(1=$ not at all; $7=$ very much $)$.

Similarity perception. The general similarity of the Spaniards and the Greeks was measured using two items. One used a scroll function, which allowed researchers to mark a precise answer on a scale ranging from 0 (not at all similar to the Greeks) to 100 (very similar to the Greeks). The second item also measured perceived similarity using a different 7-point Likert type scale $(1=$ not at all; $7=$ very $m u c h)$. Following those items and measuring general difference versus similarity, participants were asked to assess similarity related to specific domains in life. Six items, measured on the same 7-point scale as the item that assessed

\footnotetext{
${ }^{5}$ We also measured and controlled for feelings of anxiety using the same type of scale.
}

general similarity, concerned the following aspects: values, religious beliefs and practices, style of living, work habits, types of jobs performed, and job expectancies (salary, type of employment, etc.).

Identification with the outgroup. Participants were asked to evaluate how close and identified they felt with the Greeks. Three items measuring closeness, identification, and a sense of unity $(\alpha=.92)$ were based on the identification scale (solidarity subscale) developed by Leach et al. (2008). Identification was measured using a 7 -point Likert type scale $(1=$ not at all; $7=$ very much).

Solidarity with the outgroup. Participants were asked to indicate how they would react upon hearing a Greek person expressing anger related to the current economic situation. Two items measured whether the participant would empathize and sympathize with that person $(\alpha=.87)$, and two items assessed to what extent the participant would show solidarity with or offer emotional support to that person $(\alpha=.92)$. Because all the items addressed the same issue of emotional and social support related to solidarity-based reactions towards Greeks (Drury et al., 2016) and loaded on a single factor, we calculated one solidarity index $(\alpha=.94)$. All items were rated on a 7 -point scale $(1=$ not at all; 7 = very much).

Finally, participants were asked to indicate their faculty, their academic year, gender, and nationality.

\section{Results}

We applied one-way ANOVA tests to compare the differences in the dependent measures after the control manipulation.

Manipulation check. Participants reported feeling less control in the uncontrollability priming condition than in the controllability priming condition, low control: $M=2.74, S D=0.93$ vs. high control: $M=3.36$, $S D=0.65 ; \quad F(1,101)=14.32, p<.001, \quad \eta^{2}=.124$. They also agreed more strongly with the statement that the economic crisis makes them feel a lack of control over things that happen in their daily life in the uncontrollable versus controllable condition, $M=3.71, S D=0.84$ vs. $M=3.16, S D=0.93 ; F(1$, $101)=9.98, p=.002, \eta^{2}=.090$. There were no significant differences between conditions with respect to participants' beliefs about whether they have any control on the development of the crisis $(F<1$, ns).

Social perception. In the uncontrollability condition, participants perceived the Greeks as being more competent, $M=4.84, \quad S D=0.98$ vs. $M=3.78$, $S D=1.30 ; F(1,101)=22.61, p<.001, \eta^{2}=.183$, and warmer, $M=5.09, S D=1.09$ vs. $M=4.29, S D=1.27$; $F(1,101)=11.68, p=.001, \eta^{2}=.104$, than in the controllability condition. 
Perceived similarity. We compared the assessments of similarity between the Spanish people and the Greeks. On the scroll bar for the measure of general similarity (ranging from 0 [not at all] to 100 [very much]), participants rated their similarity to Greeks significantly higher in the uncontrollability versus controllability condition, $M=64.16, S D=17.29$ vs. $M=43.89, S D=22.86 ; F(1,101)=26.26, p<.001$, $\eta^{2}=.206$.

We also checked on which specific issues the Spaniards and the Greeks are assessed as being similar or different. We measured seven aspects of life to assess the specific similarities. A multivariate ANOVA revealed a main effect of the condition; that is, a sense of uncontrollability (vs. controllability) made the participants rate Greeks as being more similar to Spaniards, $F(6,96)=6.38, p<.001, \eta^{2}=.285$. This pattern of results was present for six measured aspects of life (overall, values, style of life, work habits, types of work performed, and salary), but not for one (beliefs and religious practices).

Identification. We found significantly higher identification with the Greeks for participants who experienced uncontrollability versus controllability, $M=$ $4.64, S D=1.10$ vs. $M=3.66, S D=1.28 ; F(1,101)=$ $17.46, p<.001, \eta^{2}=.147$.

Solidarity with the outgroup. As for the other measures, we found that experienced uncontrollability leads to more solidarity-based responses to the Greek outgroup than controllability, $M=5.51, S D=0.83$ vs. $M=4.58, \quad S D=1.49 ; \quad F(1,101)=16.05, \quad p=.001$, $\eta^{2}=.137$.

Mediational analyses. To test whether similarity mediates the effects of uncontrollability on perceptions of competence and warmth of the outgroup, we performed an indirect effect analysis with 10,000 bootstrap resamples using PROCESS (Hayes, 2013; Model $4)$. We found a significant indirect effect of uncontrollability on outgroup competence and warmth perceptions through similarity perceptions $(I E=.7055$, $S E=.1479$, bias-corrected 95\% CI: 0.4390, 1.0287; $I E=.7106, \quad S E=.1522, \quad$ bias-corrected $95 \% \quad \mathrm{CI}:$ $0.4440,1.0453$ for competence and warmth, respectively).

Assuming that perceived identification (recategorization) with the outgroup is the process that leads to higher perceived similarity we performed sequential mediation analyses, with two mediators, perceived identification (M1) and similarity (M2) with 10,000 bootstrap resamples using PROCESS (Hayes, 2013; Model 6), testing the effects of uncontrollability on outgroup competence and warmth assessments (see Figure 1). We found a significant indirect effect of uncontrollability on perceived outgroup competence through identification and similarity (indirect effect uncontrollability - identification - similarity - competence, $I E=.3037, S E=.1028$, bias-corrected $95 \% \mathrm{CI}$ :
0.1464, 0.5630; indirect effect uncontrollability-identification-competence; $I E=.1794, S E=.1134$, biascorrected 95\% CI: 0.0046, 0.4641; indirect effect uncontrollability-similarity-competence;

$I E=.2495, \quad S E=.1097$, bias-corrected $95 \% \quad \mathrm{CI}:$ $0.0705,0.5123$ ) and on perceived outgroup warmth (indirect effect uncontrollability-identification-similarity-warmth, $I E=.2768, S E=.0967$, bias-corrected 95\% CI: 0.1291, 0.5281; indirect effect uncontrollability-identification-warmth; $I E=.2432, S E=.1292$, bias-corrected 95\% CI: 0.0419, 0.5561; indirect effect uncontrollability—similarity-warmth, $I E=.2274$, $S E=.1077$, bias-corrected 95\% CI: 0.0623, 0.4951).

We also tested whether identification and perceived similarity mediate the effect of uncontrollability on solidarity towards the outgroup in relation to the economic crisis (Figure 2). We observed a significant indirect effect of uncontrollability through identification and similarity on solidarity towards the outgroup (indirect effect uncontrollability-identification-similarity-solidarity, $I E=.2139, \quad S E=.1077$, bias-corrected 95\% CI: 0.0549, 0.4932; indirect effect uncontrollability-identification-solidarity, $I E=.3511$, $S E=.1433$, bias-corrected 95\% CI: 0.1363, 0.7122; indirect effect uncontrollability — similarity — solidarity; $I E=.1757, S E=.0965$, bias-corrected 95\% CI: $0.0323,0.4242)$.

\section{Discussion}

In this study, we examined intergroup perception in a sample of final-year students of Spanish universities who were threatened by a proximal perspective of unemployment related to the economic crisis. After being reminded of their personal uncontrollability (vs. controllability), they perceived the Greek outgroup members to be more competent and warm, and they expressed more solidarity towards the Greeks in relation to the economic crisis. Importantly, the more positive perception of the outgroup after control threat in the context of unemployment was driven by higher identification with the outgroup and perceived similarity with its members. Furthermore, identification and similarity with the outgroup enhanced solidarity with the outgroup. These results are consistent with previous research, which showed that the inclusion of the in- and outgroup into one common category can lead to more positive, prosocial, and solidarity-based reactions (Gaertner \& Dovidio, 2000; Thomas, McGarty, \& Mavor, 2009). Our study revealed that a lack of control can extend group boundaries, enhance perceived similarities, and breed solidarity with an outgroup that is in a similar socioeconomic context. It seems that a framing related to the economic crisis that affected countries such as Greece or Spain most strongly set the ground for a common categorization level. Our findings show that identification and perhaps also recategorization with a different social group can be a powerful tool in combating threat to personal control when the 


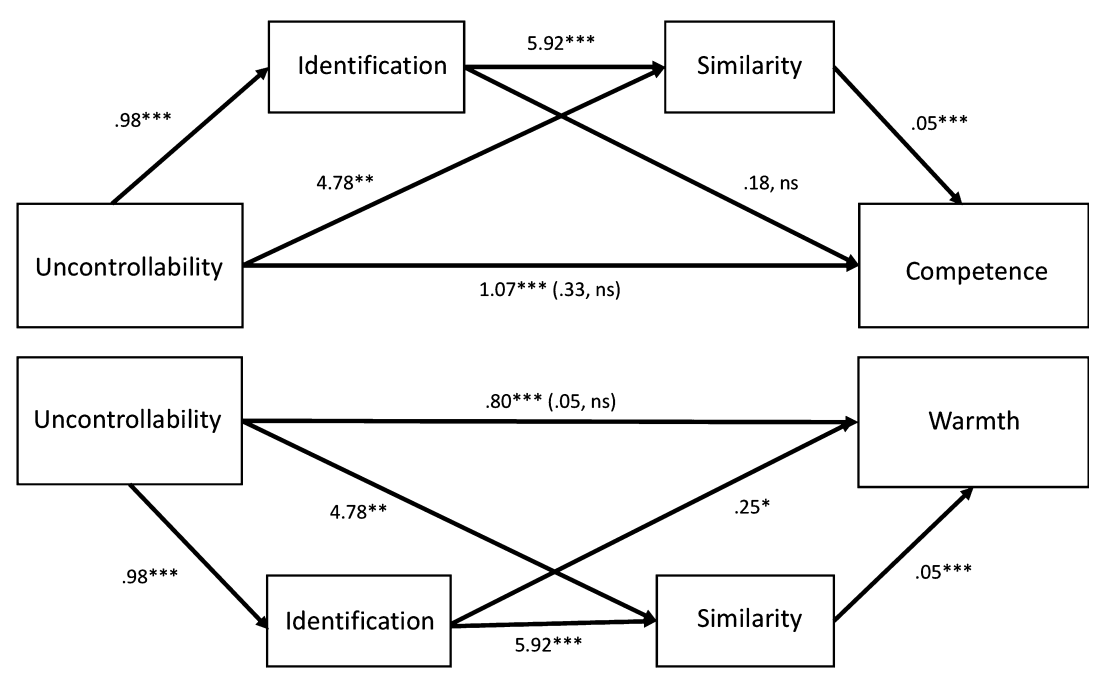

Fig. 1: Study 3. Mediation model of control manipulation on competence and warmth perceptions. Unstandardized estimates are reported. Note: $* * * p<.001 ; * * p<.01, * p<.05$

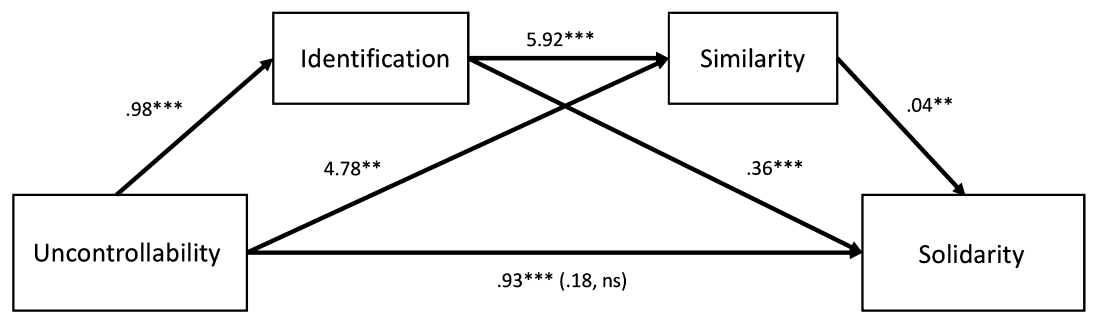

Fig. 2: Study 3. Mediation model of control manipulation on solidarity perception. Unstandardized estimates are reported. Note: $* * * p<.001 ; * * p<.01, * p<.05$

ingroup by itself cannot efficiently cope with uncontrollability.

\section{General Discussion}

When experiencing a personal lack of control, people are motivated and able to apply various coping strategies that help them restore a sense of personal control or agency (Bukowski, de Lemus, et al., 2017; Swann \& Jetten, 2017). Recent findings suggest that group identification can act as a shield against the negative effects of deprived personal control (Fritsche et al., 2013; Greenaway, Haslam, Branscombe, Cruwys, \& Ysseldyk, 2015). Turning to the ingroup as a form of control restoration on the collective-self level can lead to both defensive and outgroup-derogating responses, as well as involvement in action on behalf of agentic ingroups (Fritsche et al., 2017). These two forms of coping described in the literature can have largely different consequences for intergroup relationships. Previous research emphasized the role of recategorization processes as a way of overcoming the defensive mechanisms that follow reminders of uncontrollability (Giannakakis \& Fritsche, 2011). Other findings highlighted the importance of intergroup similarity for promoting empathy-based reactions to outgroups (LotzSchmitt, Siem, \& Stürmer, 2017; Stürmer, Snyder,
Kropp, \& Siem, 2006). Still, the conditions in which personal uncontrollability (vs. controllability) can lead to the enhanced perception of intergroup similarity and decreased prejudice remained unanswered. Consistent with previous literature on group-based control restoration, persistent personal uncontrollability can lead to a shift from the personal towards the social self (Fritsche et al., 2013). We assumed that when a personal lack of control is made salient and the ingroup agency is low (e.g., due to unemployment), people might cope with uncontrollability by increasing perceived closeness and similarity with outgroup members who share a common fate, such as when both face similar socioeconomic problems. Across the three studies performed on different populations but sharing the same state of either being unemployed or being faced with a high probability of unemployment, we showed that lack of control does not necessarily lead to defensive reactions, but can also promote constructive ways to deal with it based on intergroup proximity.

What are the conditions that seem to favor greater intergroup closeness under lack of control? Firstly, collective uncontrollability that limits the expected possibilities with which to restore personal control on a group level appears to be an important factor that can breed more positive intergroup perceptions and evaluations. Secondly, the type of outgroup matters; people 
will not drastically change their intergroup perceptions after experiencing uncontrollability towards different sorts of outgroups, but they might get closer to those groups with which they share some common socioeconomic circumstances, or even types of enemies (e.g., political groups).

\section{Uncontrollability, Group Agency, and Intergroup Perception}

When uncontrollability becomes a shared state that defines the ingroup and is difficult to change due to social labels or stigmatization (e.g., "unemployed"), restoring control by referring to one's own group and identifying with it might become problematic. In such situations, uncontrollability can promote a shift from an individualistic and independent focus on the pursuit of personal goals to a more collectivistic and interdependent one that focuses on collective social problems (Fritsche et al., 2017; Markus, 2017). Consistent with the group-based control model (Fritsche et al., 2013), self-categorization in terms of a greater collective that has the potential to achieve common goals can help to restore personal control. So far, most literature focused on ingroups as potential providers of group agency and personal control (Stollberg, Fritsche, \& Jonas, 2017; Stollberg et al., 2015). However, not only identification with group members from one's own social category can serve as a strategy to cope with uncontrollability. Closeness and identification with members of other groups who face similar social problems might also be an efficient way to deal with personal lack of control. As shown in our research, this is especially the case when one own group has a low potential to restore control (e.g., low group agency as in the case of the unemployed). Thus, our findings are coherent with the group-based control model and add an observation that those who experience not only personal but also collective uncontrollability tend to show more connectedness with members of other social categories than their counterparts who believe in their ability to exert control. Because humans are especially sensitive to patterns of coordinated actions and strategic alliances between groups, shared uncontrollability experiences can paradoxically promote this search for allies and coalitions (Cosmides, Tooby, \& Kurzban, 2003). When uncontrollability becomes a reality (being), not a temporary threat (becoming), searching for closeness and cooperation might be the only way to move on. For example, persistent discrimination might be an experience that can increase perceived similarity with other groups that are targets of discrimination or stigmatization (triggering a common ingroup categorization) and elicit coalitional attitudes (Craig \& Richeson, 2012, 2016). Perceiving coalitions or referring to a superordinate category was shown to increase positive intergroup perception (Cosmides et al., 2003; Gaertner \& Dovidio, 2000).

In our research, we found preliminary evidence to support the idea that conditions of collective uncontrollability or even helplessness, related to unemployment and economic threat, accompanied by feelings of decreased personal control might promote intergroup closeness. It involves a more inclusive social categorization and more positive intergroup perceptions and evaluations. We think that this appears to be a coping strategy that might enhance intergroup solidarity. Presumably by doing so, it can also boost collective agency (i.e., the ability to achieve a common goal; Fritsche et al., 2013). Our findings (especially those from Study 3) revealed that unemployment threat leads people to perceive certain outgroups as more agentic, trustworthy, and similar in terms of group norms. It seems reasonable for an economically disadvantaged group to form a strategic alliance or coalition with a group with whom one can effectively act together, trust one another, and rely on similar rules of conduct. Still, we find this enhanced evaluation of competence for some outgroups (such as the Greeks in Study 3), but not for other outgroups (such as the Moroccans in Study 2).

\section{Who Can be an Ally? Types of Groups Matter}

Importantly, in this research we focused on social perceptions and evaluations of outgroups that share similar socioeconomic life conditions and are affected by a sense of uncontrollability to a similar extent. Previous research examined various aspects of intergroup proximity, such as solidarity or helping, but mainly focused on a relationship in which a more powerful or higherstatus group supported the powerless outgroup (Saab, Tausch, Spears, \& Cheung, 2014; Stewart et al., 2016). Research performed in the framework of the common ingroup identity model (Gaertner \& Dovidio, 2000) revealed that commonality-focused messages can blur group boundaries and increase political solidarity between minorities (Glasford \& Calcagno, 2012). In fact, enhanced social bonds and reduced stereotyping of outgroups can be due to a tendency to take the perspective of the outgroup, which is enhanced when the outgroup's situation is similar to that of the ingroup's members (Galinsky, Ku, \& Wang, 2005). We focused on intergroup perceptions held by groups that face similar situational conditions of high uncontrollability. Even though the groups varied in terms of social and cultural similarities (e.g., Spaniards and Moroccans or Polish and immigrants from post-Soviet republics) and possible common goals resulting from the current socioeconomic situation, we found a positive relationship between lower personal control and more favorable intergroup attitudes. However, we did not find this pattern for a group that was perceived to be more threatening and heterogeneous, such as immigrants from Eastern Europe in Spain (Study 2). This finding is consistent with previous research performed in the United States by Butz and Yogeeswaran (2011), who found higher levels of prejudice in conditions of macroeconomic threat towards groups that are perceived as competent (i.e., threatening to scarce 
employment possibilities, such as Asian immigrants in the United States). We also observed more positivity towards groups that are not posing realistic threats to the ingroup but who share a low control and power position (i.e., Moroccans or immigrants from former Soviet republics). Interestingly, in Study 2, we also found a tendency to blame powerful groups (i.e., the government, corporations). This result is consistent with previous research, showing that social enemies can help to cope with uncontrollability (Sullivan \& Stewart, 2017). Hence, group members who experience uncontrollability do not show an undifferentiated positivity towards all outgroups but rather a motivated perception of similarities with groups that are in a similar social situation.

But how can those findings be reconciled with the existing literature that shows that people defend and justify the social system in response to threats by using stereotypes (Jost, Banaji, \& Nosek, 2004)? In the light of research on system justification motives, the experience of closeness among groups affected by the same socioeconomic conditions might be yet another side effect of self-stereotyping as a low-status group. Based on the system justification theory, one could assume that low-status groups accept their disadvantaged position and the status quo. This should, however, happen only when their satisfaction with the system is not very low (Jost et al., 2012). Otherwise, when the sociopolitical system is not responding to the demands of disadvantaged groups, there might be a scope for intergroup solidarity. According to the social identity theory (Tajfel \& Turner, 1979), it is important to differentiate between stable and unstable disadvantaged positions to understand intergroup relations. Unstable and illegitimate status differences can lead to social competition and ingroup favoritism by those attempting to improve their group's status within the existing social hierarchy. However, when status systems are perceived as stable and difficult to change, lower-status individuals might engage in identity management (Tajfel \& Turner, 1979). In these stable conditions, coping strategies that are focused on changing the identification level and getting closer to outgroup members who share the experience of uncontrollability and face analogous social problems might increase the possibility of an otherwise unrealistic social change. Our research does not provide information about the functionality of the observed phenomena of intergroup closeness and solidarity. They might serve the aim of enhancing perceived control among lowstatus groups and motivating them to take collective actions against a socioeconomic system that perpetuates the inequalities.

Taking a broader theoretical perspective, our results seem also consistent with other research that shows increased motivation for social closeness, more communal focus and interdependent self-construals among powerless or low-status group members (Guinote, Cotzia, Sandhu, \& Siwa, 2015; Guinote $\delta$ Lammers, 2017; Piff, Stancato, Martinez, Kraus, \&
Keltner, 2012). We believe that even though this research stems from different theoretical backgrounds and focuses on different research questions, there is a possible common mechanism that can account for the effects of more other-oriented focus in conditions of low power and status that is based on an increased sense of uncontrollability. Lacking control over the outcomes of one's behavior is an inherent element of the experience of powerlessness and low status (Fiske \& Berdahl, 2007; Kraus, Piff, \& Keltner, 2009). It might be argued that participants of our studies who were unemployed or threatened by unemployment felt not only lacking control but also power or status. Still, our results consistently show that connectedness was triggered by perceived lowered personal control. Future research should focus more on the exact relations between uncontrollability, powerlessness and status in real social settings (e.g., unemployment).

In sum, our findings showed that even in personally and collectively uncontrollable conditions, people are willing and able to search for intergroup similarities and reveal positivity towards other social category members. Still, there might be side effects of those processes; increasing closeness to certain groups and distance from others can also fuel the growing social polarization based on differences in perceived personal and collective control.

\section{Acknowledgements}

This research was supported by a research grant from the Polish National Science Centre $(\mathrm{NCN})$ awarded to the first author (DEC-2014/15/G/HS6/04529). The work on this article was also supported by grants awarded by the Spanish Ministry of Economy and Competitiveness to the second author (PSI201679971-P) and to the third author (PSI2016-78839). We would like to thank Piotr Dragon and Laura Navarro Mantas for helping with conducting Study 1 and 2, and Immo Fritsche for his valuable comments on an earlier version of this article.

\section{Supporting Information}

Additional supporting information may be found online in the Supporting Information section at the end of the article.

\section{References}

Becker, J. C., Wagner, U., \& Christ, O. (2011). Consequences of the 2008 financial crisis for intergroup relations: The role of perceived threat and causal attributions. Group Processes $\theta$ Intergroup Relations, 14, 871-885. https://doi.org/10.1177/1368430211407643 
Brewer, M. B., Hong, Y. Y., \& Li, Q. (2004). Dynamic entitativity: Perceiving groups as actors. In V. Yzerbyt, C. M. Judd, \& O. Corneille (Eds.), The psychology of group perception. Perceived variability, entitativity, and essentialism (pp. 25-38). New York, NY: Psychology Press.

Brown, R. (1984). The role of similarity in intergroup relations. In H. Tajfel (Ed.), The social dimension: European developments in social psychology (European studies in social psychology (pp. 603-623). Cambridge, UK: Cambridge University Press.

Bukowski, M., de Lemus, S., Rodriguez-Bailón, R., \& Willis, G. B. (2017). Who's to blame? Causal attributions of the economic crisis and personal control. Group Processes $\theta$ Intergroup Relations, 20, 909-923. https://doi.org/10. $1177 / 1368430216638529$

Bukowski, M., Fritsche, I., Guinote, A., \& Kofta, M. (2017). Coping with lack of control in a social world: An introduction. In M. Bukowski, I. Fritsche, A. Guinote, \& M. Kofta (Eds.), Coping with lack of control in a social world (pp. 1-12). London, UK: Routledge.

Burger, J. M., \& Cooper, H. M. (1979). The desirability of control. Motivation and Emotion, 3, 381-393. https://doi. org/10.1007/BF00994052

Butz, D., \& Yogeeswaran, K. (2011). A new threat in the air: Macroeconomic threat increases prejudice against Asian Americans. Journal of Experimental Social Psychology, 47, 22-27. https://doi.org/10.1016/j.jesp.2010.07.014

Campbell, D. T. (1958). Common fate, similarity, and other indices of the status of aggregates of persons as social entities. Systems Research $\theta$ Behavioral Science, 3, 14-25. https://doi.org/10.1002/bs.3830030103

Cassidy, T. (2001). Self-categorization, coping and psychological health among unemployed mid-career executives. Counselling Psychology Quarterly, 14, 303-315. https://doi.org/10.1080/09515070110102800

Cikara, M., Bruneau, E. G., \& Saxe, R. R. (2011). Us and them: Intergroup failures of empathy. Current Directions in Psychological Science, 20, 149-153. https://doi.org/10. 1177/0963721411408713

Cosmides, L., Tooby, J., \& Kurzban, R. (2003). Perceptions of race. Trends in Cognitive Sciences, 7, 173-179. https://d oi.org/10.1016/1364-6613(03)00057-3

Craig, M. A., \& Richeson, J. A. (2012). Coalition or derogation? How perceived discrimination influences intraminority intergroup relations. Journal of Personality and Social Psychology, 102, 759-777. https://doi.org/10. 1037/a0026481

Craig, M. A., \& Richeson, J. A. (2016). Stigma-based solidarity: Understanding the psychological foundations of conflict and coalition among members of different stigmatized groups. Current Directions in Psychological Science, 25, 21-27. https://doi.org/10.1177/0963721415611252

Creed, P. A., \& Bartrum, D. A. (2008). Personal control as a mediator and moderator between life strains and psychological well-being in the unemployed. Journal of Applied Social Psychology, 38, 460-481. https://doi.org/10.1111/j. 1559-1816.2007.00313.x

Creed, P. A., Hood, M., \& Leung, L. Y. (2012). The relationship between control, job seeking, and well-being in unemployed people. Journal of Applied Social Psychology, 42, 689-701. https://doi.org/10.1111/ j.1559-1816.2011. 00798.x
Cuddy, A. J. C., Fiske, S. T., \& Glick, P. (2007). The BIAS map: Behaviors from intergroup affect and stereotypes. Journal of Personality and Social Psychology, 92, 631-648. https://doi.org/10.1037/0022-3514.92.4.631

Dovidio, J. F., Gaertner, S. L., \& Validzic, A. (1998). Intergroup bias, status, differentiation, and a common ingroup identity. Journal of Personality and Social Psychology, 75, 109-120. https://doi.org/10.1037//00223514.75.1.109

Drury, J., Brown, R., González, R., \& Miranda, D. (2016). Emergent social identity and observing social support predict social support provided by survivors in a disaster: Solidarity in the 2010 Chile earthquake. European Journal of Social Psychology, 46, 209-223. https://doi.org/10. 1002/ejsp.2146

Esses, V., \& Zanna, M. (1995). Mood and the expression of ethnic stereotypes. Journal of Personality and Social Psychology, 69, 1052-1068. https://doi.org/10.1037//0022-3514. 69.6.1052

Faul, F., Erdfelder, E., Lang, A., \& Buchner, A. (2007). G* power 3: A flexible statistical power analysis program for the social, behavioral, and biomedical sciences. Behavior Research Methods, 39, 175-191. https://doi.org/10.3758/bf 03193146

Fiske, S. T., \& Berdahl, J. (2007). Social power. In A. Kruglanski \& E. T. Higgins (Eds.), Social psychology: Handbook of basic principles (2nd ed., pp. 678-692). New York, NY: Guilford.

Fiske, S., Cuddy, A., Glick, P., \& Xu, J. (2002). A model of (often mixed) stereotype content: Competence and warmth respectively follow from perceived status and competition. Journal of Personality and Social Psychology, 82, 878-902. https://doi.org/10.1037//0022-3514.82.6.878

Fritsche, I., Jonas, E., Ablasser, C., Beyer, M., Kuban, J., Manger, A.-M., \& Schultz, M. (2013). The power of we: Evidence for group-based control restoration. Journal of Experimental Social Psychology, 49, 19-32. https://doi.org/ 10.1016/j.jesp.2012.07.014

Fritsche, I., Jonas, E., \& Fankhänel, T. (2008). The role of control motivation in mortality salience effects on ingroup support and defense. Journal of Personality and Social Psychology, 95, 524-541. https://doi.org/10.1037/ a0012666

Fritsche, I., Jonas, E., \& Kessler, T. (2011). Collective reactions to threat: Implications for intergroup conflict and solving societal crises. Social Issues and Policy Review, 5, 101136. https://doi.org/10.1111/j.1751-2409.2011.01027.x

Fritsche, I., \& Jugert, P. (2017). The consequences of economic threat for motivated social cognition and action. Current Opinion in Psychology, 18, 31-36. https://doi.org/ 10.1016/j.copsyc.2017.07.027

Fritsche, I., Moya, M., Bukowski, M., Jugert, P., de Lemus, S., Decker, O., ... Navarro-Carrillo, G. (2017). The great recession and group-based control: Converting personal helplessness into social class ingroup trust and collective action. Journal of Social Issues, 73, 117-137. https://doi. org/10.1111/josi.12207

Gaertner, S. L., \& Dovidio, J. F. (2000). Reducing intergroup bias: The common ingroup identity model. Philadelphia, PA: Psychology Press.

Galinsky, A. D., Ku, G., \& Wang, C. S. (2005). Perspectivetaking and self-other overlap: Fostering social bonds and 
facilitating social coordination. Group Processes $\theta$ Intergroup Relations, 8, 109-124. https://doi.org/10.1177/ 1368430205051060

Giannakakis, A. E., \& Fritsche, I. (2011). Social identities, group norms, and threat: On the malleability of ingroup bias. Personality and Social Psychology Bulletin, 37, 82-93. https://doi.org/10.1177/0146167210386120

Glasford, D. E., \& Calcagno, J. (2012). The conflict of harmony: Intergroup contact, commonality and political solidarity between minority groups. Journal of Experimental Social Psychology, 48, 323-328. https://doi.org/ 10. 1016/j.jesp.2011.10.001

Goffman, E. (1963). Stigma; notes on the management of spoiled identity. Englewood Cliffs, NJ, Prentice-Hall.

González, R., \& Brown, R. (2003). Generalization of positive attitude as a function of subgroup and superordinate group identification in intergroup contact. European Journal of Social Psychology, 33, 195-214. https://doi.org/10. $1002 /$ ejsp. 140

Greenaway, K. H., Haslam, S. A., Branscombe, R. N., Cruwys, T., \& Ysseldyk, R. (2015). From "we" to "me": Group identification enhances perceived personal control with consequences for health and well-being. Journal of Personality and Social Psychology, 109, 53-74. https://doi.org/10.1037/pspi0000019

Greenaway, K. H., Louis, W. R., Hornsey, M. J., \& Jones, J. M. (2014). Perceived control qualifies the effects of threat on prejudice. British Journal of Social Psychology, 53, 422-442. https://doi.org/10.1111/bjso.12049

Guinote, A., Cotzia, I., Sandhu, S., \& Siwa, P. (2015). Social status modulates prosocial behavior and egalitarianism in preschool children and adults. Proceedings of the National Academy of Sciences, USA, 112, 731-736. https://d oi.org/10.1073/pnas.1414550112

Guinote, A., \& Lammers, J. (2017). Accentuation of tending and befriending among the powerless. In $\mathrm{M}$. Bukowski, I. Fritsche, A. Guinote, \& M. Kofta (Eds.), Coping with lack of control in a social world (pp. 185-202). New York, NY: Routledge.

Hannan, D. F., O'Riain, S., \& Whelan, C. T. (1997). Youth unemployment and psychological distress in the Republic of Ireland. Journal of Adolescence, 20, 307-320. https://doi.org/10.1006/jado.1997.0087

Hayes, A. F. (2013). Introduction to mediation, moderation, and conditional process analysis. New York, NY: Guildford Press.

Henderson-King, E., Henderson-King, D., Zhermer, N., Posokhova, S., \& Chiker, V. (1997). In-group favoritism and perceived similarity: A look at Russians' perceptions in the post-Soviet era. Personality and Social Psychology Bulletin, 10, 1013-1021. https://doi.org/10.1177/ 01461672972310002

Hoenig, J. M., \& Heisey, D. M. (2001). The abuse of power: The pervasive fallacy of power calculations in data analysis. The American Statistician, 55, 19-24. https://doi.org/ 10.1198/000313001300339897

INE. (2015). Tasas de paro por distintos grupos de edad, sexo y comunidad autónoma. Retrieved October 3, 2017 from http://www.ine.es/jaxiT3/Datos.htm?t=4247

Jost, J. T., Banaji, M. R., \& Nosek, B. A. (2004). A decade of system justification theory: Accumulated evidence of conscious and unconscious bolstering of the status quo.
Political Psychology, 25, 881-919. https://doi.org/10. 31234/osf.io/6ue35

Jost, J. T., Chaikalis-Petritsis, V., Abrams, D., Sidanius, J., van der Toorn, J., \& Bratt, C. (2012). Why men (and women) do and don't rebel: Effects of system justification on willingness to protest. Personality and Social Psychology Bulletin, 38, 197-208. https://doi.org/10.1177/ 0146167211422544

Kossowska, M., Hanusz, K., \& Trejtowicz, M. (2012). Skrócona wersja Skali Potrzeby Poznawczego Domknięcia: Dobór pozycji i walidacja skali [Short version of the Need for Cognitive Closure Scale: Items selection and scale validation]. Psychologia Społeczna, 9, 89-99.

Kraus, M. W., Piff, P. K., \& Keltner, D. (2009). Social class, sense of control, and social explanation. Journal of Personality and Social Psychology, 97, 992-1004. https://doi.org/ 10.1037/a0016357

Leach, C. W., van Zomeren, M., Zebel, S., Vliek, M. L. W., Pennekamp, S. F., Doosje, B., ... Spears, R. (2008). Group-level self-definition and self-investment: A hierarchical (multicomponent) model of in-group identification. Journal of Personality and Social Psychology, 95, 144165. https://doi.org/10.1037/0022-3514.95.1.144

Lemm, K. M., Lane, K. A., Sattler, D. N., Khan, S. R., \& Nosek, B. A. (2008). Assessing implicit cognitions with a paper-format Implicit Association Test. In M. A. Morrison \& T. G. Morrison (Eds.), The psychology of modern prejudice (pp. 121-146). New York, NY: Nova Science Publishers.

Lotz-Schmitt, K., Siem, B., \& Stürmer, S. (2017). Empathy as a motivator of dyadic helping across group boundaries: The dis-inhibiting effect of the recipient's perceived benevolence. Group Processes $\theta$ Intergroup Relations, 20, 233-259. https://doi.org/10.1177/1368430215612218

Markus, H. R. (2017). In this together: Doing and undoing inequality and social class divides. Journal of Social Issues, 73, 211-221. https://doi.org/10.1111/josi.12212

Martínez, C., \& Vera, J. (1994). La estructura del prejuicio: Realidad y simbolismo. Boletín de Psicología, 42, 21-38.

McConahay, J. B., Hardee, B. B., \& Batts, V. (1981). Has racism declined in America? It depends upon who is asking and what is asked. Journal of Conflict Resolution, 25, 563-579. https://doi.org/10.1177/002200278102500401

Merolla, J. L., Ramos, J. M., \& Zechmeister, E. J. (2007). Crisis, charisma, and consequences: An experimental study during the 2004 U.S. election. Journal of Politics, 69, 30-42. https://doi.org/10.1111/j.1468-2508.2007.00492. $\mathrm{X}$

Murphy, G. C., \& Athanasou, J. (1999). The effect of unemployment on mental health. Journal of Occupational and Organizational Psychology, 72, 83-99. https://doi.org/ 10.1348/096317999166518

Navas, M. S. (1998). Nuevos instrumentos de medida para el nuevo racismo. Revista de Psicología Social, 13, 233-239. https://doi.org/10.1174/021347498760350731

Pew Research Center. (2013). Retrieved July 24, 2018 from http://www.pewglobal.org/2013/05/13/the-new-sickman-of-europe-the-european-union/

Piff, P. K., Stancato, D. M., Martinez, A. G., Kraus, M. W., \& Keltner, D. (2012). Class, chaos, and the construction of community. Journal of Personality and Social Psychology, 103, 949-962. https://doi.org/10.1037/a0029673 
Pittman, T. S. (1998). Motivation. In D. T. Gilbert, S. T. Fiske, \& G. Lindzey (Eds.), The handbook of social psychology (vol. 1, 4th ed., pp. 549-590). New York, NY: McGraw-Hill.

Portos, M. (2016). Movilización social en tiempos de recesión: Un análisis de eventos de protesta en España, 2007-2015. Revista Española de Ciencia Política, 41, 159178. https://doi.org/10.21308/recp.41.07

Pratto, F., Sidanius, J., Stallworth, L. M., \& Malle, B. F. (1994). Social dominance orientation: A personality variable predicting social and political attitudes. Journal of Personality and Social Psychology, 67, 741-763. https://doi. org/10.1037//0022-3514.67.4.741

Price, R. H., Choi, J. N., \& Vinokur, A. D. (2002). Links in the chain of adversity following job loss: How financial strain and loss of personal control lead to depression, impaired functioning, and poor health. Journal of Occupational Health Psychology, 7, 302-312. https://doi.org/10. 1037//1076-8998.7.4.302

Riumallo-Herl, C., Basu, S., Stuckler, D., Courtin, E., \& Avendano, M. (2014). Job loss, wealth and depression during the Great Recession in the USA and Europe. International Journal of Epidemiology, 43, 1508-1517. https://d oi.org/10.1093/ije/dyu048

Saab, R., Tausch, N., Spears, R., \& Cheung, W. (2014). Acting in solidarity: Testing an extended dual-pathway model of collective action by bystander group members. British Journal of Social Psychology, 54, 539-560. https://d oi.org/10.1111/bjso.12095

Sears, D. O. (1988). Symbolic racism. In P. A. Katz \& D. A. Taylor (Eds.), Eliminating racism: Profiles in controversy (pp. 53-85). New York, NY: Plenum.

Skinner, E. A. (1996). A guide to constructs of control. Journal of Personality and Social Psychology, 71, 549-570. https://doi.org/10.1037//0022-3514.71.3.549

Stewart, A. L., Pratto, F., Bou Zeineddine, F., Sweetman, J., Eicher, V., Licata, L., ... van Stekelenburg, J. (2016). International support for the Arab uprisings: Understanding sympathetic collective action using theories of social dominance and social identity. Group Processes $\theta$ Intergroup Relations, 19, 6-26. https://doi.org/10.1177/ 1368430214558310

Stollberg, J., Fritsche, I., \& Bäcker, A. (2015). Striving for group agency: Threat to personal control increases the attractiveness of agentic groups. Frontiers in Psychology, 6 , 649. https://doi.org/10.3389/fpsyg.2015.00649

Stollberg, J., Fritsche, I., Barth, M., \& Jugert, P. (2017). Extending control perceptions to the social self: Ingroups serve the restoration of control. In M. Bukowski, I. Fritsche, A. Guinote, \& M. Kofta (Eds.), Coping with lack of control in a social world (pp. 133-150). London, UK: Routledge.

Stollberg, J., Fritsche, I., \& Jonas, E. (2017). The groupy shift: Conformity to liberal ingroup norms as a groupbased response to threatened personal control. Social Cognition, 35, 374-394. https://doi.org/10.1521/soco.2017. 35.4.374
Stürmer, S., Snyder, M., Kropp, A., \& Siem, B. (2006). Empathy-motivated helping: The moderating role of group membership. Personality and Social Psychology Bulletin, 32, 943-956. https://doi.org/ 10.1177/ 0146167206287363

Sullivan, D., \& Stewart, S. A. (2017). Perceived uncontrollability as a coping resource: The control-serving function of enemies and uncertainty. In M. Bukowski, I. Fristche, A. Guinote, \& M. Kofta (Eds.), Coping with lack of control in a social world (pp. 97-115). London, UK: Routledge.

Swann, W. B. Jr, \& Jetten, J. (2017). Restoring agency to the human actor. Perspectives on Psychological Science, 12, 382-399. https://doi.org/10.1177/1745691616679464

Tajfel, H., \& Turner, J. C. (1979). An integrative theory of intergroup conflict. In W. G. Austin \& S. Worchel (Eds.), The social psychology of intergroup relations (pp. 33-47). Monterey, CA: Brooks/Cole.

Thomas, E. F., McGarty, C., \& Mavor, K. I. (2009). Aligning identities, emotions, and beliefs to create commitment to sustainable social and political action. Personality and Social Psychology Review, 13, 194-218. https://doi.org/10. 1177/1088868309341563

Turner, J. C., Hogg, M. A., Oakes, P. J., Reicher, S. D., \& Wetherell, M. S. (1987). Rediscovering the social group: A self-categorization theory. Oxford, UK: Blackwell.

Warburton, W. A., Williams, K. D., \& Cairns, D. R. (2006). When ostracism leads to aggression: The moderating effects of control deprivation. Journal of Experimental Social Psychology, 42, 213-220. https://doi.org/10.1016/ j.jesp.2005.03.005

Warr, P. B. (1987). Work, unemployment, and mental health. Oxford, UK: Clarendon.

White, R. (1959). Motivation reconsidered: The concept of competence. Psychological Review, 66, 297-330. https://d oi.org/10.1037/h0040934

Whitson, J. A., \& Galinsky, A. D. (2008). Lacking control increases illusory pattern perception. Science, 322, 115117. https://doi.org/10.1126/science.1159845

Wilkinson, R. G., \& Pickett, K. (2017). The enemy between us: The psychological and social costs of inequality. European Journal of Social Psychology, 47, 11-24. https://doi. org/10.1002/ejsp.2275

Wilson VanVoorhis, C. R., \& Morgan, B. L. (2007). Understanding power and rules of thumb for determining sample sizes. Tutorials in Quantitative Methods for Psychology, 3, 43-50. https://doi.org/10.20982/tqmp.03.2.p043

Wirtz, C., \& Doosje, B. (2013). Reactions to threatening critical messages from minority group members with shared or distinct group identities. European Journal of Social Psychology, 43, 50-61. https://doi.org/10.1002/ejsp. 1910

Zumbo, B. D., \& Hubley, A. M. (1998). A note on misconceptions concerning prospective and retrospective power. Journal of the Royal Statistical Society Series D (The Statistician), 47, 385-388. https://doi.org/10.1111/14679884.00139 